\title{
COMUNICAÇÃo PÚBLICA E DIPLOMACIA PÚBLICA: UMA ANÁLISE QUANTITATIVA E QUALITATIVA DA PÁGINA DO MINISTÉRIO DAS RELAÇÕES EXTERIORES BRASILEIRO NO FACEBOOK
}

\begin{abstract}
Resumo
Este artigo tem por objetivo analisar a página oficial, presente no Facebook, do Ministério das Relações Exteriores brasileiro em uma perspectiva quantitativa e qualitativa. Com o intuito de averiguar se o ministério promove comunicação pública de Estado e diplomacia pública. Foram analisados 1562 posts, coletados pelo aplicativo Netvizz em 2017, da página oficial com base na proposta teórica de observar os de pontos convergentes/intersecções, entre três perspectivas teóricas: a comunicação pública, a diplomacia pública e a diplomacia pública 2.0.

A metodologia empregada é a revisão bibliográfica, dados quantitativos do volume de engajamento (soma dos números de reações, dos comentários e dos compartilhamentos) e da classificação dos posts nas 8 categorias qualitativas propostas - Ações de Diplomacia/Comunicação voltadas para Público Brasileiro; Ações de Diplomacia/Comunicação voltadas para Público Estrangeiro; Posicionamento, Custos/Orçamentos/Investimentos; Agenda; Políticas Públicas; Participação e Curiosidades/Post de preenchimento. Os dados foram processados no software SPSS. Verificou-se a predominância de postagens que buscavam aumentar o nível de informação do usuário sobre o ministério e de postagens que pretendiam estabelecer uma atmosfera de boa vontade e sociabilidade, entretanto, houve uma ocorrência ínfima de postagens que buscavam incentivar a participação do usuário/cidadão. Existe também um alto volume de engajamento em postagens que representavam o povo brasileiro como Estado Nação e de publicações que eram direcionadas a sociedade brasileira. Os resultados mostram que apesar do ministério afirmar promover perspectivas da diplomacia pública, e por conseguinte, da comunicação pública de Estado raramente posta conteúdo relacionado. E os o engajamento na página mostra que os usuários interagem mais quando há conteúdo da sociedade civil. Apesar de existir intersecções entre as teorias, não há muitas pesquisas na área de comunicação que relacione esses questionamentos teóricos com pesquisas empíricas, sendo voltada muito para a área de Relações Internacionais. Assim, é benéfica a relação interdisciplinar com a comunicação política.
\end{abstract}

Palavras-Chaves: comunicação pública; diplomacia pública; diplomacia pública 2.0; facebook; ministério das relações exteriores.

\section{INTRODUÇÃO}

As dinâmicas da política contemporânea, seja no âmbito doméstico, seja nas relações internacionais mudaram por causa das novas perpesctivas em rede. Além disso, é responsável pela transformação nas percepções da sociedade sobre as decisões do Estado; isto é, há maior demanda para a participação da sociedade nas deliberações e negociações do Estado sobre as definições de suas políticas externas, assim como no próprio Estado.

\footnotetext{
1. Mestranda em Comunicação Social no Programa de Pós-graduação da Universidade Federal do Paraná (UFPR), npc_cardoso@hotmail.com.
} 
As decisões tomadas também sofrem influência da opinião pública em espaços de comunicação online - além daquela comunicação mediada tradicionalmente, a exemplo da televisão, do rádio e dos meios impressos, como o jornal, que ainda detêm grande parcela da audiência (BRASIL, 2016). Não obstante, os espaços digitais de comunicação são cada vez mais utilizados, como observada pela agência We are Social, em parceria com a plataforma de mídia Hootsuite, no Relatório Digital de Mídia (2019) no qual destaca o Facebook como o segundo site de rede social mais acessado por usuários de internet no Brasil (90\%).

O Ministério das Relações Exteriores é o órgão da administração pública federal responsável pelas relações do Brasil com os demais países e pela participação brasileira em organizações internacionais, assim como, executar a política externa definida pela Presidência da República conforme os princípios estabelecidos no art. $4_{2}^{\circ}$ da Constituição Federal (ITAMARATY, 2017).

A comunicação pública trabalha com as várias formas que a comunicação é empregada pelo Estado- uma organização com poder de tomar decisões que afetam a sociedade civil e que abrangem temas que são voltados para o interesse público (MIOLA \& MARQUES, 2017). Já a diplomacia pública - e, atualmente, da diplomacia 2.0 - é pautada porque trata-se de ações de comunicação voltadas para um público mais amplo e realizadas por um ator internacional com o intuito de (1) representar; (2) negociar; (3) proteger; e (4) promover. Este ator internacional pode vir a ser um Estado, uma multinacional, uma organização não governamental, uma organização internacional, uma organização terrorista/ organização paramilitar apátrida ou outro participante no cenário mundial (CULL, 2008).

Levando em consideração a percepção que existe a influência da sociedade civil nas decisões do Estado; que a Diplomacia é um campo no qual essa premissa também se aplica; e que as pesquisas sobre o assunto dentro do campo da Comunicação são escassas, este artigo propõem pôr em diálogo conceitos sobre comunicação pública, diplomacia pública, de modo a contemplar contextos mediados pelas tecnologias da comunicação em rede. Esses contextos digitais, inclusive, têm suscitado a denominação específica da articulação diplomacia pública-comunicação online como "diplomacia pública 2.0".

\footnotetext{
2 A República Federativa do Brasil rege-se nas suas relações internacionais pelos seguintes princípios: (1)independência nacional; (2) prevalência dos direitos humanos; (3) autodeterminação dos povos; (4) não-intervenção; (5) igualdade entre os Estados; (6) defesa da paz; (7) solução pacífica dos conflitos; (8) repúdio ao terrorismo e ao racismo; (9) cooperação entre os povos para o progresso da humanidade e (10) concessão de asilo político (BRASIL, 1988).
} 
O objeto deste estudo é tomado do ponto de vista teórico da comunicação porque, embora, a diplomacia pública e a diplomacia pública digital sejam conceitos pautados por ações e estratégias comunicacionais, esses conceitos raramente são analisados pelo viés da comunicação, mas sim, das Relações Internacionais.(INSERIR REFERENCIAS)

Portanto, o presente artigo pretende observar qualitativamente e quantativamente as postagens do Ministério das Relações Exteriores brasileiro no ano de 2015 até o primeiro semestre do ano de 2017, com $N=1562$ posts da página oficial - em português - com o intuito de observar se e como a instituição promove diplomacia pública e comunicação pública de Estado no Facebook.

\section{COMUNICAÇÃO PÚBLICA}

O conceito de comunicação pública perpassa por diversas áreas do conhecimento e por diversos objetos de pesquisas, como Comunicação Organizacional, Comunicação Científica, Relações de Poder e Práticas comunicativas comunitárias ou da sociedade civil, e por isso as suas delimitações teóricas são difíceis. Assim, deve-se primeiro entender a construção do conceito de comunicação pública e suas variantes.

A pesquisa levantada por Marina Koçouski (2012) sobre a área demonstra que existe quatro correntes teóricas principais. A primeira corrente é ligada a concepção de esfera pública habermasiana, no qual a comunicação ocorre no espaço público de uma determinada sociedade sobre a forma de uma rede complexa de transações informais, expressivas e solidárias; ou seja; o "público" é livre para questionar os setores sistêmicos e simultaneamente, sofre a influências deles. “Em outras palavras, a ‘comunicação pública’ habermasiana é uma 'comunicação do público' [...] pode ser considerada como uma parte do conceito do qual estamos tratando, mas não o próprio conceito." (KOÇOUSKI, 2012, p.73)

Já a segunda é recorrente do pensamento de que a comunicação pública é delineada pela legitimidade do interesse geral - resultado de pactos entre indivíduos e grupos da sociedade interligados por um "contrato social" - e propaga-se além do âmbito público referido conforme o senso jurídico. Acredita que as mensagens são realizadas, emitidas, recebidas e tratadas por organizações públicas em nome da sociedade, e, por conseguinte, não podem ser separadas das funções intrínsecas das instituições públicas como (1) informar; (2) escutar; (3) contribuir para assegurar a relação social e; (4) acompanhar as mudanças de comportamento e das organizações 
sociais. Nessa perspectiva o Estado é o articulador principal da comunicação pública. (ZÉMOR, 2012; KOÇOUSKI, 2012)

Entretanto, essa forma de comunicação pode representar um meio para se criar a personalização ou para ocorrer a apropriação das causas de interesse público em prol de ideias políticas, da promoção ou propaganda de interesses concorrentes, específicos ou partidários; dado que atinge uma grande parte da população de um país. Ou seja, a dimensão estratégica.

Visa a conquista e a manutenção de poder por grupos ou atores políticos, especialmente a partir, da construção de imagens ou representações sociais positivas dos atores ou instituições que concorrem pela avaliação favorável da opinião pública. É interessante ressaltar que essas ações de comunicação são responsáveis por criar a confiança nas instituições e por ajudar na estabilidade política, e consequentemente, a legitimidade dos governos, mas que, de outra forma, podem ser utilizadas para a obtenção de benefícios particulares - de atores ou de partidos políticos -, o que desvirtua alguns ideais da comunicação pública (ZÉMOR, 2012; KOÇOUSKI, 2012; MIOLA \& MARQUES, 2017).

A perspectiva da América Latina, e a terceira levantada pela pesquisa, abordada que esse tipo de comunicação é originado da relação entre a comunicação e a política, considerando que público é aquilo que é de todos e que a política é o espaço de construção de consensos. A comunicação pública pode abarcar cinco dimensões: 1) Política - é a construção de bens públicos, de propostas políticas e denominada 'comunicação política', assim como pertencer a um âmbito mais amplo de comunicação pública; 2) Mediática - é a relação com os meios de comunicação, manifestações culturais por intermédio do entretenimento e a orientação para a gestão da informação e para a criação de agenda pública; 3) Estatal - é a interação comunicativa entre o governo e a sociedade; 4) Organizacional - é uma organização, privada ou pública, no qual grupos tentam predominar e impor interesses; e; 5) Vida social - são ações comunicativas espontâneas ou não, de movimentos e organizações sociais, que ao interagir propõem propostas de interesse público e coletivo.(LÓPEZ, 2012)

Existe também a definição da comunicação pública através de níveis de comunicação, sendo: a) Informação- capacidade de informar e de ser informado; b) Consulta- capacidade de consultar e ser consultado por meio de entrevistas, pesquisas, grupos específicos, mesas de consulta e sondagens de opinião; c) Deliberação- capacidade de deliberar e reconhecer os argumentos do outro; d) Consenso- capacidade de apresentar e negociar os próprios interesses em mesas de negociação ou debate, e; e) Corresponsabilidade- capacidade de assumir compromissos de forma 
corresponsável, mediante uma administração compartilhada. É defendido também o conceito de advocacy (advocacia) - termo que expressa o ato de "defender uma causa" ou "promover uma política" - como uma ação de comunicação pública, já que se trata de uma ação que convoca e constrói propósitos comuns em busca da formação de sentidos compartilhados relativos a assuntos de interesse coletivo. (LÓPEZ, 2012)

O quarto e último ponto de vista mostra que a comunicação pública deve promover o aumento da informação, que é um direito do cidadão. É dividida em três dimensões: 1) Promotores ou emissores - são organizações públicas, privadas ou semipúblicas; 2) Finalidade - são objetivos que não devem ser orientados por questões comerciais ou econômicas; e; 3) Objeto - são "interesses gerais" que dizem respeito a sociedade como um todo. Para se entender melhor a dimensão Objeto e os “interesses gerais", é necessário compreender as noções de publicidade e sociedade civil, que embora não serem provenientes da comunicação pública ou da comunicação de Estado, são originarias da teoria democrática. A publicidade é vista como a abertura das instituições, de uma forma acessível e disponível, para prover informações de interesse público. Não obstante, a publicidade não pode ser só assegurada pelas notícias jornalísticas já que as empresas jornalísticas levam em conta outros interesses, como o econômico. Já a sociedade civil entende-se como um conjunto de organizações que se articulam para ajudar no funcionamento do sistema social vigente. (KOÇOUSKI, 2012; HALLIN \&MANCINI, 2004; FILGUEIRAS, 2011)

No Brasil o estudo sobre comunicação publica só começou a ser pensado e discutido depois da redemocratização do país em 1985 e da garantia de direitos como liberdade de expressão e de imprensa, e, a divulgação transparente das ações do governo, vigentes na Constituição federal de 1988. Uma proposta de sistematização da literatura na área da comunicação pública pode levar em conta: quem "faz" a comunicação, qual é a natureza do conteúdo que é produzido, quais são os veículos utilizados, o lugar do público no processo comunicativo e a comunicação pública democrática-normativa (MIOLA \& MARQUES, 2017). Entretanto, a principal vertente nesse artigo é o a visão democrática-normativa.

A comunicação de Estado cumpre um papel chave na concretização da democracia, visto que as ações na área podem contribuir para aprimorar valores e práticas no esquema democrático ((LÓPEZ, 2012; MIOLA \& MARQUES, 2017). O campo de interação entre a comunicação e a democracia aponta contribuições normativas relevantes para a comunicação pública. As ações mais observadas são aquelas que podem aproximar cidadãos e representantes por meio do apoio à participação - principalmente os meios digitais; da melhora nos fluxos administrativos e a entrega 
de serviços - governo eletrônico; do aumento da transparência e da prestação de contas dos governos - abertura e acessos a bancos de dados, sites online de transparência e demais ações que facilitem a realização da lei de acesso à informação. Essa visão de comunicação de Estado baseada na própria teoria democrática - no qual pode ser dividida em três categorias: (1) Transparência e accountability; (2) Participação e (3) Prestação de serviços.

As ações comunicacionais, e por conseguinte, as ações de comunicação pública de Estado perpassam a internet e os sites de rede sociais. Esse novo meio disponibilizou novos recursos para potencializar a comunicação como a hipertextualidade, a mutimedialidade e a interatividade, da mesma forma, possibilitou a participação digital com o conteúdo criado pelo usuário, o compartilhamento de informações e os diálogos. Isso fez com que atores públicos começassem a buscar múltiplos canais que os ligassem aos cidadãos. (NASCIMENTO, 2012; ALMADA et al., 2014)

A internet e mais especificamente as redes sociais colocariam o processo de comunicação com o cidadão como ponto central, não somente pelo direito a informação, mas também pelo diálogo e incitação à participação ativa. Da mesma forma que a rede social impulsionou a comunicação pública, impulsionou, por conseguinte, as práticas democráticas (ALMADA et al., 2014). Uma nova área de estudos que apesar de não ser proveniente das pesquisas na área de comunicação, possui uma similaridade muito importante, o de ser uma iniciativa de caráter e interesse público. Essa nova área é chamada de Diplomacia Pública.

\section{DIPLOMACIA PÚBLICA E SUA VERSÃO 2.0}

Antes de entrarmos propriamente nas definições de diplomacia pública devemos primeiramente entender o que é diplomacia. Na Convenção de Viena, em termos abrangentes, foi definido que a diplomacia contém quatro propósitos principais, (1) Representar; (2) Negociar; (3) Proteger e (4) Promover os interesses de um Estado perante terceiros (SÁNCHEZ, 2014). O autor Nicholas Cull $(2008,2009)$ ainda complementa que essa prática consiste em mecanismos, que não a guerra, no qual um ator internacional utiliza para tentar gerenciar o ambiente internacional. É importante relembrar que um "ator internacional", hoje em dia, pode vir a ser um Estado, corporação multinacional, organização não governamental, organização internacional, organização terrorista / organização paramilitar apátrida ou outro jogador no cenário mundial. (CULL, 2009) 
A forma tradicional de diplomacia é baseada na tentativa do ator internacional em gerenciar o ambiente externo através do engajamento com outro(s) ator(es) internacional(is). Esta forma tradicional geralmente é empregada na Diplomacia Secreta, já que a sua execução é restrita a atores convencionais de direito, como: ministros, burocratas e Estados (ALBA Z, 2009) Entretanto, com o crescimento da participação da sociedade civil nas esferas de decisões das políticas externas, essa forma de diplomacia foi abrindo espaço para uma nova variação, a diplomacia pública.

Conforme explica o autor Cull, "a diplomacia pública é uma tentativa de um ator internacional gerenciar o ambiente internacional por meio do engajamento com um público estrangeiro" (CULL, 2009, p.12). Essa variação consiste, então, no crescimento da atividade diplomática para além dos espaços tradicionais e restritos anteriormente atribuídos ao ato diplomático (de chanceleres, diplomatas, políticos e lideranças internacionais), alcançando assim um público mais amplo (PERON, 2017; ROLO, 2014; CULL, 2008, CULL, 2009). O aspecto fundamental que distinguem a diplomacia pública da diplomacia tradicional é o fato de que a informação deve ser pública e transparente, e não secreta ou "opaca" voltada especificamente para públicos da cúpula política e econômica de outros países (NOYA, 2006).

A diplomacia pública também é apontada por Leonardo Valente (2007) como a comunicação direta com os públicos estrangeiros, assim, o seu intuito é influenciar sua forma de pensar e suas opiniões sobre algum tema que seja de interesse do ator internacional que esteja executando essa ação. As contribuições de Cull (2009) envolvem uma categorização dessas práticas de diplomacia pública a partir de seis elementos principais: listening, advocacia, diplomacia cultural, exchange diplomacy, transmissão internacional e guerra psicológica.

Em suas considerações sobre a obra de Cull, Peron (2017) aponta que não podemos confundir a forma com o conceito. Em outras palavras, a autora afirma que a categorização de Cull classifica praticamente todo o tipo de troca ou intercâmbio simbólico como diplomacia pública - o que, muitas vezes, deixa de lado a participação social na tomada de decisões de políticas e posicionamentos externos. No entanto, considera-se que essa categorização interliga a ação diplomática com a difusão de informação/conteúdo ou processos comunicacionais de larga escala, podendo então levar à dedução de que a "diplomacia pública se refere aos princípios de atuação da atividade diplomática junto ao público, através de diferentes ações (sejam presenciais ou mediadas por meios de comunicação; sejam estes digitais ou analógicos) ” (PERON, 2017, p.4). Essas deliberações presentes entre os diversos públicos e atores internacionais dentro da diplomacia pública também envolvem relações de poder e, mais especificamente, o conceito de soft power. 
A dimensão de publicidade dessa variante de diplomacia coloca em evidência o ato de “tornar públicas” as informações relativas às tomadas de decisões sobre políticas externas, ou seja, a expansão da atividade diplomática e o maior fluxo de interação com diversos atores. Assim, se a diplomacia pública é o engajamento da atividade diplomática voltada para públicos mais amplos por meio de processos informacionais e comunicacionais, ela também deve estar presente nos meios digitais, sendo nomeada como: diplomacia pública 2.0. (CULL, 2008, 2009; NYE, 2008; PERON, 2017; ROLO, 2014)

Desde de 2000, com o advento da Web 2.0, os atores políticos, sejam no âmbito internacional ou não, utilizam as tecnologias da comunicação em rede como mecanismo de divulgação e de diálogo uma vez que a interatividade, a conexão social e o conteúdo gerado pelo usuário tornaram-se um elemento relevante na formação da identidade humana individual e nas articulações entre sociedade e Estado (NORRIS, 2000; DAHLBERG, 2001; MARQUES, 2016). A nova configuração da internet também proporcionou uma nova configuração na diplomacia pública, pois apresenta (1) aumento da importância da opinião pública sobre a política externa; (2) ênfase no diálogo e na (3) reciprocidade. Assim, houve uma mudança na diplomacia pública que passou a ser digital e denominada como Diplomacia Pública 2.0. (CULL, 2010)

As novas configurações sociais demostram que os cidadãos são protagonistas, pois as relações sociais na internet permitem que um novo tipo de entendimento internacional; não somente as relações de político para político, de líder para líder; mas sim de cidadão para cidadão e de pessoa para pessoa - e de cidadão para líderes, acrescenta-se. É evidente a importância da diplomacia digital, pois não se trata apenas de produzir sua própria informação, mas também de distribuir informações de/para terceiros, de forma apropriada para cada público, sem negligenciar abordagens que sejam mais interessantes para os usuários de internet, como o infoentretenimento, e ações que facilitem a construção de prestígio por parte do emissor da mensagem .

A reputação ou prestígio é o capital mais importante dos Estados para quem a comunicação estatal deve se basear na credibilidade para construir a imagem do país de acordo com os interesses do Estado. As relações internacionais, assim como a política, tornaram-se uma competição por credibilidade e, na nova configuração das sociedades em rede, os atores internacionais não são só governos, mas também as medias, as empresas, as ONGs, a sociedade, etc. Nesse contexto, a multiplicidade de atores se torna um dos principais desafios da nova estrutura da diplomacia pública, pois não é suficiente, sem planejamento e estratégias. Esses atores, a exemplo do Estado, fazem uso de estratégias de comunicação tendo em vista três posicionamentos de comunicação 
midiática: 1) enquadramento, 2) definição de agenda e 3) priorização (RUBIO, 2011). Através dessas ferramentas, os Estados podem direcionar e exercer influência sobre as informações prioritárias para a sociedade, favorecendo assim a construção da imagem que pretendem projetar sobre o país. É importante ressaltar que, em uma diplomacia de rede como a que surge, a falta de coordenação e planejamento estratégico produz impactos negativos sobre a sinergia entre os diversos atores envolvidos (RUBIO, 2011). Do mesmo modo que, não é possível pensar a diplomacia pública sem a diplomacia digital nos tempos atuais, como não é possível pensar a comunicação contemporânea sem as mídias sociais. (RUBIO, 2011; ROLO, 2014)

\subsection{INTERSECÇÕES TEÓRICAS \& QUADRO ANALÍTICO}

Nessa secção do artigo será abordada as intersecções teóricas da comunicação pública com os conceitos de diplomacia pública e de diplomacia pública 2.0, buscando apresentar definições ou estratégias semelhantes entre as teorias, e assim, a construção de um quadro analítico.

Observa-se a convergência possível entre o conceito de comunicação pública de Estado e o conceito de diplomacia pública na medida em que certos princípios que orientam as atividades de representação de uma atividade são semelhantes à outra. Adicionalmente, se a comunicação pública de Estado pode lançar mão dos mais diversos meios e plataformas de comunicação para dar visibilidade às ações de agentes políticos, assim também, potencialmente, o faz a diplomacia pública. Consequentemente, as expansões da comunicação midiática para os ambientes de comunicação digital, por um lado, ampliam as formas de interação, divulgação e prestação de contas, por outro, afetam as expectativas e as demandas do público em relação à presença das instituições nas redes.

O próprio caráter da diplomacia, que consiste em mecanismos que não a guerra, empregadas por um ator internacional, para gerenciar o ambiente internacional, deixa em aberto a possibilidade de se empregar estratégias que são da competência da comunicação para que ocorra essa gerência de uma forma não invasiva (CULL, 2008, 2009, 2010; PERON, 2017). Por exemplo, a ação de Advocacia (Defender uma causa) que é vista tanto como uma ação de comunicação como de diplomacia pública, já que consiste em convocar e construir propósitos comuns em busca de formação de sentidos compartilhados relativos a assuntos de interesse comum. 
Outra convergência teórica é a referente aos públicos, uma vez que em um primeiro momento dos estudos nas áreas de diplomacia pública, diplomacia pública 2.0 e de comunicação pública, o ator que comunica - principalmente players de grande prestígio- não estavam interessados em estabelecer uma relação de feedback com o seu público alvo, isto é, o receptor/usuário só permanecia na primeira fase da comunicação, o de receber. Entretanto, com a mudança desta percepção por parte das organizações e da sociedade civil que começou a reivindicar o seu espaço nas rodas de tomadas de decisões, o público se tornou mais ativo e participativo na hora de expor suas ideias e realizar críticas, principalmente, por causa da internet nos quais os cidadãos são os protagonistas. Todavia, é necessário a distinção de "para quem" a ação de diplomacia pública e de comunicação pública é direcionada.

Com o passar dos anos ocorreu uma nova percepção de "para quem" as ações de diplomacia pública deveriam ser direcionadas, ou seja, as ações seriam agora voltadas para o público interno, os cidadãos do próprio país, a sua sociedade civil. Nesse novo redirecionamento os atores internacionais - principalmente os órgãos provenientes do Estado- passaram a abrir mais as organizações para a intervenção da sociedade civil, pensando em promover a transparência, prestação de contas e participação, uma vez que a diplomacia aurora de um Estado Democrático. Isso permitiu que o público interno participasse mais das tomadas de decisões, contribuísse com o direcionamento da política externa e fiscalizasse as ações realizadas no exterior em seu nome. No meio digital as relações sociais resultaram em um novo tipo de entendimento internacional, aquele que não é mais pautado em modelos verticais de poder, mas sim em horizontais. É nesta nova percepção de público que a diplomacia pública converge para a comunicação pública de Estado.

Nos seus estudos iniciais a comunicação pública já era voltada para os cidadãos brasileiros, entretanto, não seguia as diretrizes que estão presentes na própria democracia. Na comunicação pública esse mesmo aspecto, nova forma de atuar com o público, é encontrada quando o cidadão é incentivado em participar de espaços criados pelo Estado para o debate, detendo parcelas significativas, de informação, de participação e também um lugar para proferir críticas e intervenções em relação ao Estado. A internet, e mais ainda as redes sociais digitais, alavancaram essas iniciativas de práticas democráticas. No entanto podemos pensar em outra finalidade que esse novo redirecionamento de público acarretou.

Para que uma instituição e suas ações possam ser legitimadas dentro de um regime democrático é necessário que aqueles nos quais as instituições representam ou a soberania nacional reconheçam positivamente a instituição, posto que caso isso não aconteça, a população possui o 
direito de requerer a sua destituição. Essa legitimação só é possível através da comunicação pública de Estado e da diplomacia pública, que através da transparência e da prestação de contas legitimam a representação democrática. Por isso que as ações de comunicação e diplomacia voltadas para o público internas são importantes.

Assim, com o advento da proposta teórica de intersecção das áreas de comunicação pública, diplomacia pública e das novas configurações 2.0 da diplomacia; nasce o questionamento se estas propostas podem ser aplicadas para analisar os posts do Ministério das Relações Exteriores brasileiro, a fim de saber como o ministério se comunica no Facebook.

\section{METODOLOGIA}

O Facebook é um site de rede social lançado em 2004 com o intuito de facilitar a comunicação entre estudantes (KIRKPATRICK, 2011), porém, a sua finalidade vem se expandindo para além desta área. Cataloga-se a sua utilização da seguinte forma: ferramenta na educação; fonte de informação; espaço de entretenimento; oportunidade de veiculação de publicidade e propaganda, entre outras. No início, o site só disponibilizava a criação de perfis individuais de pessoas físicas, mas, com o passar do tempo, empresas e instituições -públicas ou privadas- passaram a também ter a opção de criar um tipo diferente de perfil, uma página, para poder interagir dentro do site. Esse é o caso do objeto de estudo, o Ministério das Relações Exteriores e a sua página no Facebook.

A coleta do corpus empírico foi executada na rede social Facebook em setembro de 2017 no site oficial do Ministério das Relações Exteriores, Itamaraty. Para a coleta de dados foi utilizado o aplicativo vigente na época, Netvizz, que tem por finalidade: "extrair dados de diferentes seções da plataforma Facebook, particularmente de páginas e grupos, com o intuito de pesquisa" (RIEDER, 2017). Os arquivos foram extraídos em setembro de 2017, entretanto os dados da amostra foram coletados separadamente de mês a mês do recorte temporal dos anos de 2015, 2016 e 2017 (até agosto). O recorte do objeto de estudo é este porque leva em conta o segundo ano do governo Dilma até o seu afastamento, e o início do governo Temer até o período de agosto de 2017, o que por sua vez, também garante analisar os dados de pesquisa de acordo com a variável "governo".

No total, foram coletadas 1562 postagens classificadas pelo Netvizz em tipo de publicação; podendo ser texto, link, foto ou vídeo; na quantificação do número de like, número de comentários, número de reações, número de compartilhamentos, comentários recuperados, comentários base - os comentários que deram origem a diversas respostas - número de like a comentários, respostas a 
comentários, os strings (pacotes de dados), id da postagem, link da postagem, conteúdo da postagem, picture, full picture, link, domínio do link postado e o post published (data e horário). E por último, o volume de engajamento que consiste na soma dos números de reações, dos comentários e dos compartilhamentos. Entretanto, só os indexadores - tipo de publicação- e a variável quantitativa volume de engajamento foram adicionadas na análise em conjunto com as variáveis qualitativas, referentes a diplomacia e comunicação pública.

Os procedimentos de análise empregados partem das intersecções teóricas entre comunicação pública de Estado (MIOLA e MARQUES, 2017) e diplomacia pública (CULL, 2008), com enfoque na similaridade entre as ações voltadas para o interesse público, os cidadãos brasileiros, e as que seguem os preceitos democráticos. Entretanto, deve-se falar da variável governo.

A variável governo é definida pelo período governamental que o post foi publicado na página do ministério, ou seja, se o post foi publicado em 2015 até o começo de maio de 2016 é pertencente ao período governamental de Dilma Rousseff e se foi publicado de maio de 2016 até agosto de 2017, é pertencente ao período governamental de Michel Temer.

As variáveis qualitativas foram pensadas com o intuito de abranger três dimensões que, quando somadas, resultaram em uma classificação unificada para pensar a comunicação e a diplomacia pública no Facebook, no presente contexto. A primeira dimensão é a de comunicação pública como um instrumento democrático; a segunda é a diplomacia pública com diplomacia pública 2.0 e a terceira seria esses conceitos dentro da era digital.

A grade analítica unificada, denominada de "Intersecções: Comunicação Pública, Diplomacia 2.0 e Facebook", a qual foi alicerçada na fundamentação teórica descrita neste trabalho, é dividida em três grupos de variáveis: 1) Informação, 2) Mobilização e 3) Discurso Fático. É importante ressaltar que as categorias descritas a seguir buscam entender sobre o que os posts querem "dizer" na sua forma apresentada dentro da plataforma Facebook, ou seja, somente o corpo de texto, imagético ou não, que é visto dentro da página oficial, sem a necessidade de buscar informações externas para entender a mensagem.

O grupo Informação é aquele que procura aumentar o nível de conhecimento do receptor acerca de atividades realizadas pelo/no Ministério das Relações Exteriores. Ou seja, fornece informação ao seu receptor com o intuito de promover a transparência de suas atividades ministeriais e políticas, assim como a prestação de contas- pontos convergentes entre a diplomacia pública e a comunicação pública. Esse grupo apresenta as seguintes variáveis: Ações de 


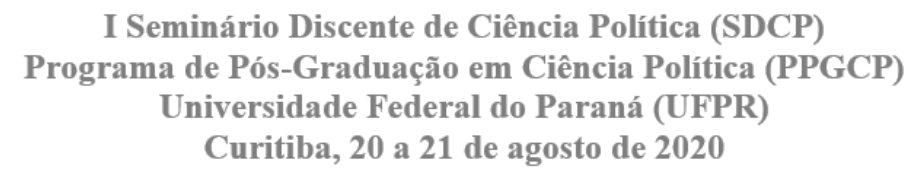

Diplomacia/Comunicação voltadas para Público Brasileiro; Ações de Diplomacia/Comunicação voltadas para Público Estrangeiro; Posicionamento, Custos/Orçamentos/Investimentos; Agenda; Políticas Públicas.

O segundo grupo, Mobilização, é aquele que busca compreender as iniciativas que tentam aumentar a mobilização social com o objetivo de tornar a sociedade civil mais presente nos âmbitos de diplomacia/comunicação. Esse grupo apresenta apenas uma categoria: a Participação. Apesar de ser apenas uma categoria, é responsável por definir posts que incentivam um conceito fundamental presente na comunicação pública e na diplomacia pública, a participação social. É composto pelo estímulo de uso de canais de participação - conferências, conselhos, questionários para consultas de opinião ou discussão sobre determinados temas, como Sustentabilidade e meio Ambiente- de criação, por intermédio do Facebook, de participação política. A participação também pode ser vista por encorajamento a utilizar os comentários para a manifestação da opinião ou avaliação do ministério ou na divulgação e promoção de outros canais de participação - sejam eles mediados, a exemplo de plataformas digitais, sejam eles tradicionais, como consultas públicas. Mas ações de interação com a própria plataforma Facebook, por exemplo, "curta ou compartilhe essa publicação", não são categorizados como participação.

O terceiro e último grupo, o Discurso Fático, é o grupo que fornece ao receptor posts que expressam ou criam atmosfera de boa vontade, sociabilidade ou compartilhamento de sentimentos. É composto pela variável Curiosidade/Post de preenchimento. Essa é a única categoria de caráter excludente, quer dizer que quando marcada, o post, não apresentou nenhuma das demais categorias. Por exemplo, um post não pode ser analisado como Participação e Curiosidade ao mesmo tempo. Geralmente, esses posts são compostos por conteúdos como dia da leitura ou troca de foto de perfil ou capa.

Com base nas propostas teóricas discorridas acima proponho o seguinte quadro analítico:

QUADRO 1:VARIÁVEIS QUALITATIVAS.

\begin{tabular}{|l|l|l|}
\hline Grupos & Categorias analisadas & Explicação \\
\hline 1. Governo & Dilma Rousseff ou Michel Temer & $\begin{array}{l}\text { Identificar em qual época governamental o post analisado } \\
\text { foi publicado. }\end{array}$ \\
\hline 2.Informação & Ações de Diplomacia/Comunicação & \multicolumn{1}{c|}{ Ações para o Público Brasileiro: } \\
& & $\begin{array}{l}\text { Interlocuções e acordos com atores internacionais } \\
\text { brasileiros (outros ministérios, governo federal, } \\
\text { organizações não-governamentais brasileiras, etc.) } \\
\text { Promoção, por parte do Itamaraty, de atividades voltadas } \\
\text { especificamente para a sociedade brasileira (prêmios, } \\
\text { promoção e elaborações de cartilhas, e etc.) } \\
\text { Informar serviços ou situações danosas como os "Alertas } \\
\text { Consulares" }\end{array}$ \\
\hline
\end{tabular}




\begin{tabular}{|c|c|c|}
\hline & & $\begin{array}{l}\text { Ações para o Público Estrangeiro: } \\
\text { Encontros de líderes como ministros e chefes de Estado } \\
\text { Promoção de jantares consulares } \\
\text { Participação em órgãos da ONU } \\
\text { Promoção da cultura brasileira em território estrangeiro, } \\
\text { ações humanitárias e etc. } \\
\text { Desempenhos de ações da diplomacia tradicional } \\
\text { (encontro entre chanceles e participações na Organização } \\
\text { das Nações Unidas- ONU) } \\
\text { Diplomacia pública para público estrangeiro (diplomacia } \\
\text { cultural, intercâmbio acadêmico entre escolas } \\
\text { diplomáticas e international broadcast) descrita por Cull } \\
\text { (2008) } \\
\text { Visão de aproximação da diplomacia com a sociedade } \\
\text { civil como especificada por Rubio (2011) } \\
\text { Incumbência informar serviços e promover a } \\
\text { transparência (MIOLA e MARQUES, 2017) }\end{array}$ \\
\hline & Posicionamentos & $\begin{array}{l}\text { Representam sempre diretrizes na forma de Estado Nação, } \\
\text { por exemplo, a Nota Oficial }\end{array}$ \\
\hline & Custos, Orçamentos e Investimentos & $\begin{array}{l}\text { Intuito de promover a transparência e prestação de conta } \\
\text { dos recursos utilizados pelo ministério ou pelo Brasil - os } \\
\text { recursos podem ser de pessoas, financeiro ou de produtos. }\end{array}$ \\
\hline & Agenda & $\begin{array}{l}\text { Expandir a informação dos cidadãos sobre quais } \\
\text { atividades o ministério e a sua alta cúpula está realizando } \\
\text { para manter o funcionamento do ministério e da obtenção } \\
\text { dos interesses definidos pela política externa e do } \\
\text { interesse nacional. }\end{array}$ \\
\hline & Políticas Públicas & $\begin{array}{l}\text { Compreende como os programas e resoluções do } \\
\text { ministério estão sendo realizadas, isto é, esclarece como } \\
\text { as ações estão sendo feitas e administradas, afetando } \\
\text { diretamente os cidadãos brasileiros- estejam presentes ou } \\
\text { não no território brasileiro. }\end{array}$ \\
\hline 3.Mobilização & Participação & $\begin{array}{l}\text { Estímulo de uso de canais de participação - conferências, } \\
\text { conselhos, questionários para consultas de opinião ou } \\
\text { discussão sobre determinados temas, como } \\
\text { Sustentabilidade e meio Ambiente- de criação, por } \\
\text { intermédio do Facebook, de participação política. A } \\
\text { participação também pode ser vista por encorajamento a } \\
\text { utilizar os comentários para a manifestação da opinião ou } \\
\text { avaliação do ministério ou na divulgação e promoção de } \\
\text { outros canais de participação - sejam eles mediados, a } \\
\text { exemplo de plataformas digitais, sejam eles tradicionais, } \\
\text { como consultas públicas. }\end{array}$ \\
\hline 4.Discurso Fático & Curiosidade/Post de preenchimento & $\begin{array}{l}\text { Expressar ou criar atmosfera de boa vontade, } \\
\text { sociabilidade ou compartilhamento de sentimentos. Essa é } \\
\text { a única categoria de caráter excludente. }\end{array}$ \\
\hline
\end{tabular}

Fonte: AUTORA, 2020. 


\section{RESULTADOS}

Os dados a seguir foram os resultados do processamento, no software de análise SPSS, da classificação qualitativa do corpus de pesquisa, do volume de engajamento e do período governamental.

O Gráfico 1 explica o tipo de publicação - Foto, Vídeo, Link, Status, Nota e Evento- em função do governo- Dilma Rousseff e Michel Temer. Posts do tipo Foto possui a maior ocorrência dentro do corpus e nos dois governos. O tipo Vídeo e Link atingiram a linha dos 100 posts no governo Dilma, mas o governo Temer apesar de não atingir a linha dos 100, não ficou muito longe. Os demais tipos - Status, Nota e Evento- não foram utilizados com frequência relevante. De modo geral o corpus de pesquisa apresenta em sua maioria posts do tipo "Foto", com 1204, seguidos de "Vídeo" com 185, de "Link" com 167, de "Status" com 3, de "Nota" com 2 e "Evento" com 1. Em contagem de post para cada período governamental, Dilma Rousseff possui 1035 posts e Michel Temer 527.

Gráfico 1: Tipo de publicação X Governo.

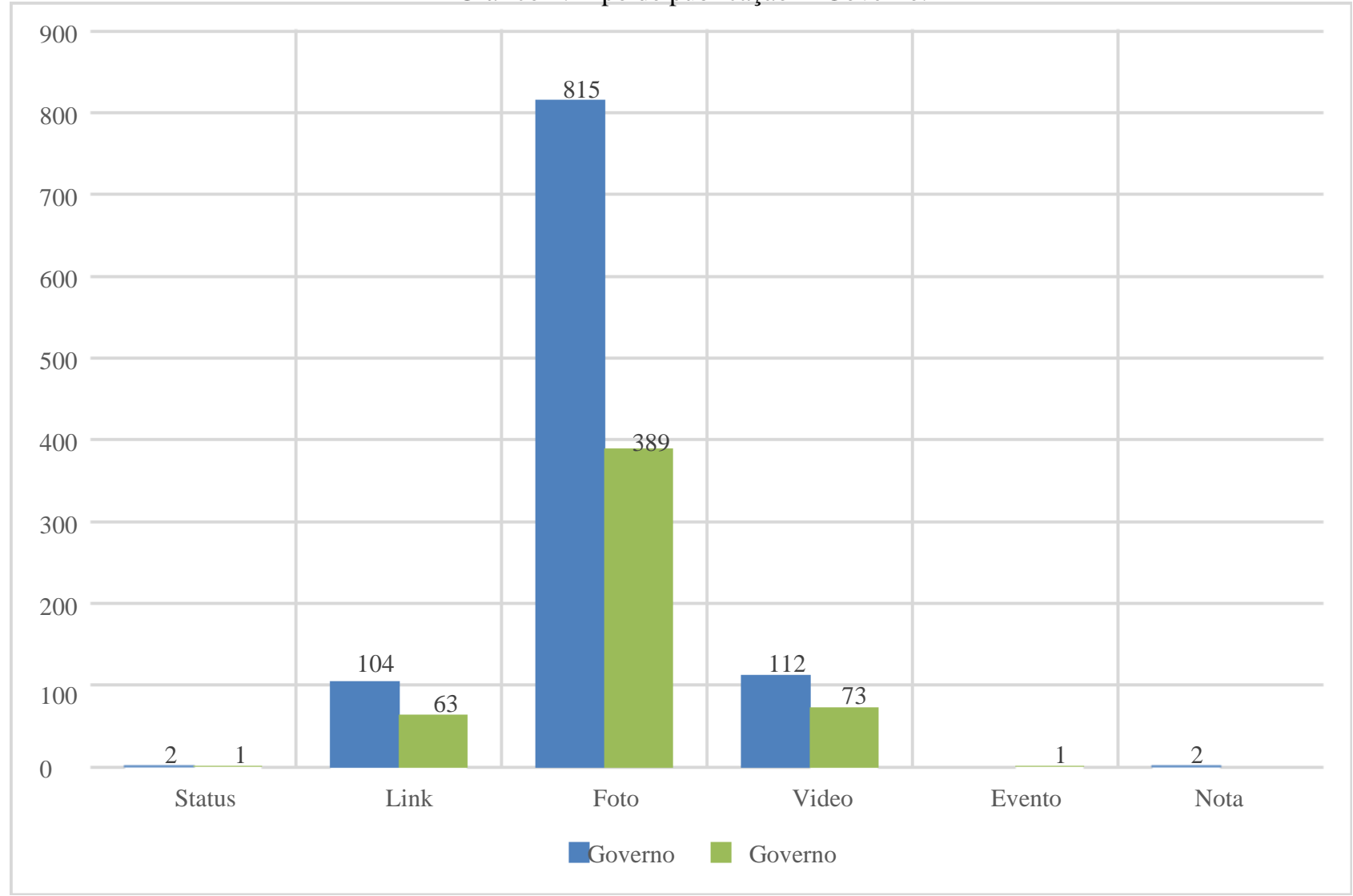

Fonte: AUTORA, 2020. 
Na Tabela 1 é possível notar a contagem geral das variáveis qualitativas juntamente com as suas médias de engajamento. As Ações de Diplomacia/Comunicação voltadas para o Público Brasileiro estão presentes em 215 posts e as Ações de Diplomacia/Comunicação voltadas para o Público Estrangeiro estão presentes em 492 posts - maior número de posts atribuído a uma variável. Entretanto, essa mesma configuração não acontece na média de engajamento, dado que as ações voltadas para o público brasileiro possuem média de aproximadamente 435 - a segunda maior média de engajamento - em comparação com a média de 240 (segunda menor média) das ações voltadas para o público estrangeiro.

Posts que foram avaliados como Posicionamento, contabilizados 218 posts, possuem a maior média de engajamento entre todas a variáveis, 817 de média. A variável de Custos, Orçamentos e Investimentos representam 108 posts do total de 1562, mas os seus posts são a terceira maior média de engajamento, 426. A categoria Agenda é a segunda maior no quesito número de posts, 460 posts; e a terceira menor média em engajamento, 281. A categoria Políticas Públicas representa somente 34 posts, mas a sua média de engajamento não é uma das mais baixas com 380. A variável qualitativa Participação representa a menor contagem de número de posts em que aparece com o ínfimo número de 5, e, o menor número de engajamento com média de 156. A última categoria, Curiosidades/Post de preenchimento, é a terceira categoria que mais retém número de posts, 415, e média de engajamento relativamente alta com 326. A média de engajamento total de todas as 1562 publicações foi de 373 .

Tabela 1: Contagem geral das variáveis qualitativas e médias de engajamento.

\begin{tabular}{|l|r|r|}
\hline Variáveis qualitativas & Média de engajamento & Número de publicações \\
\hline Ações de Diplo/Comu (Público Brasileiro) & 435,7 & 215 \\
\hline Ações de Diplo/Comu (Público Estrangeiro) & 240,6 & 492 \\
\hline Posicionamento & 817,7 & 218 \\
\hline Custos, Orçamentos e Investimentos & 426,2 & 108 \\
\hline Agenda & 281,9 & 460 \\
\hline Políticas Públicas & 380,9 & 34 \\
\hline Participação & 156,4 & 5 \\
\hline Curiosidades/Post de preenchimento & 326,8 & 415 \\
\hline Total & 373,3 & 1562 \\
\hline
\end{tabular}

Fonte: AUTORA, 2020.

Os resultados presentes na Tabela 1 podem ser melhores notados no Gráfico 2, no qual a linha azul representa a média de engajamento. 
Gráfico 2: Volume de publicações por variável X Médias de engajamento

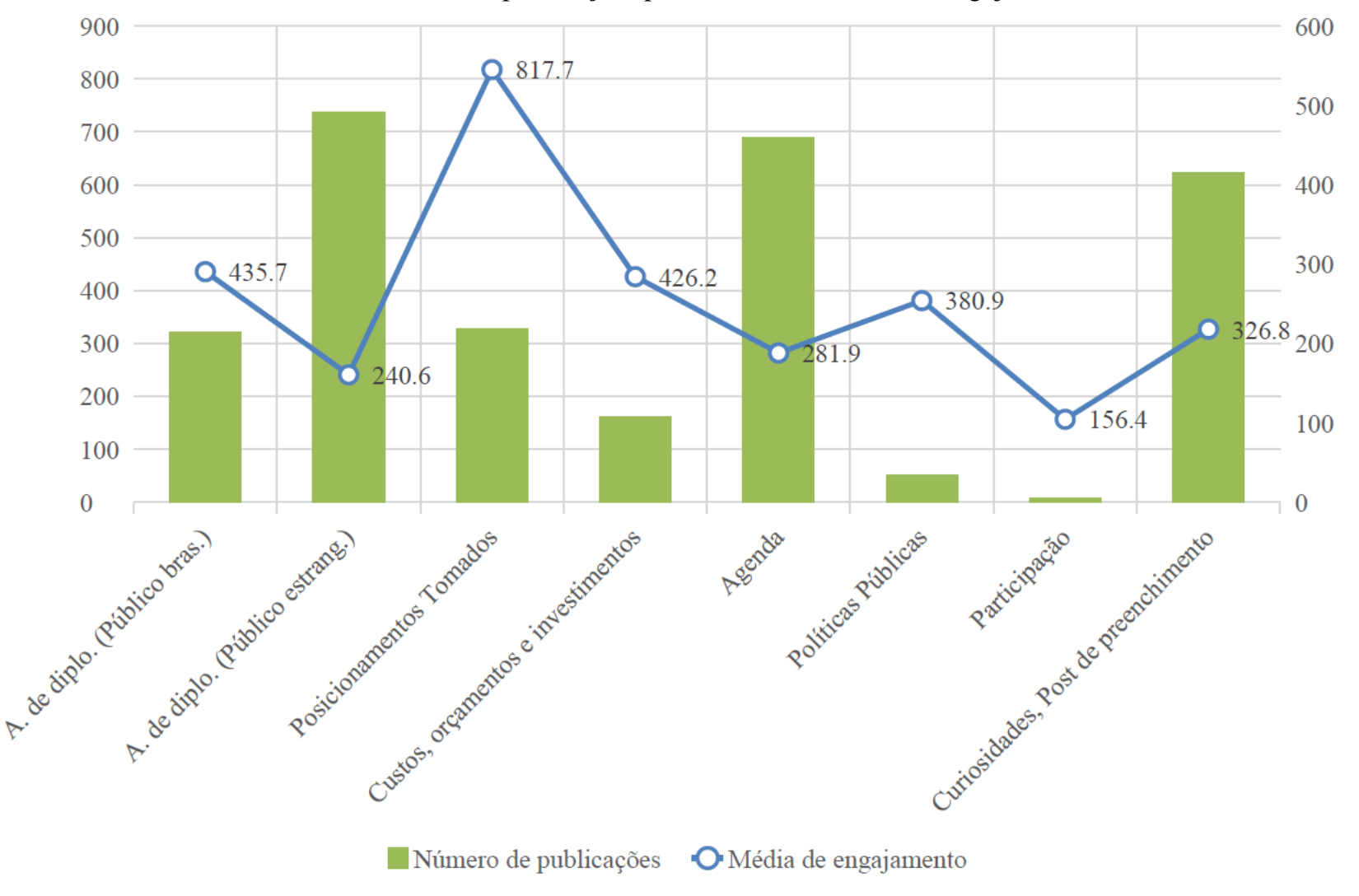

Fonte: AUTORA, 2020.

No Gráfico 3 pode-se observar as categorias qualitativas condicionadas ao período de governo - Dilma Rousseff e Michel Temer. Pelo fato de o governo Dilma Rousseff possuir 1035 posts, praticamente o dobro de Michel Temer, 527 posts, do total de 1562; é então natural pensar que no seu governo também apresente o maior número de casos em cada variável qualitativa. Entretanto, são as variáveis Agenda, Ações de Diplomacia/Comunicação voltada para Público Estrangeiro, Curiosidades/Post de preenchimento e Posicionamento, respectivamente do maior para o menor, onde o governo Dilma Rousseff mais se manifesta. Já no governo Michel Temer as variáveis mais evidenciadas, na ordem crescente, são as Ações de Diplomacia/Comunicação voltada para o Público Estrangeiro, as Curiosidades/Post de preenchimento e a Agenda. Mas, é importante ressaltar que as outras demais variáveis - Ações para Público Brasileiro, Custos/Orçamentos/Investimento e principalmente Políticas Públicas e Participação - não sofreram manifestações muito discrepantes entre os governos em questão. 
Gráfico 3: Categorias de publicação X Governo.

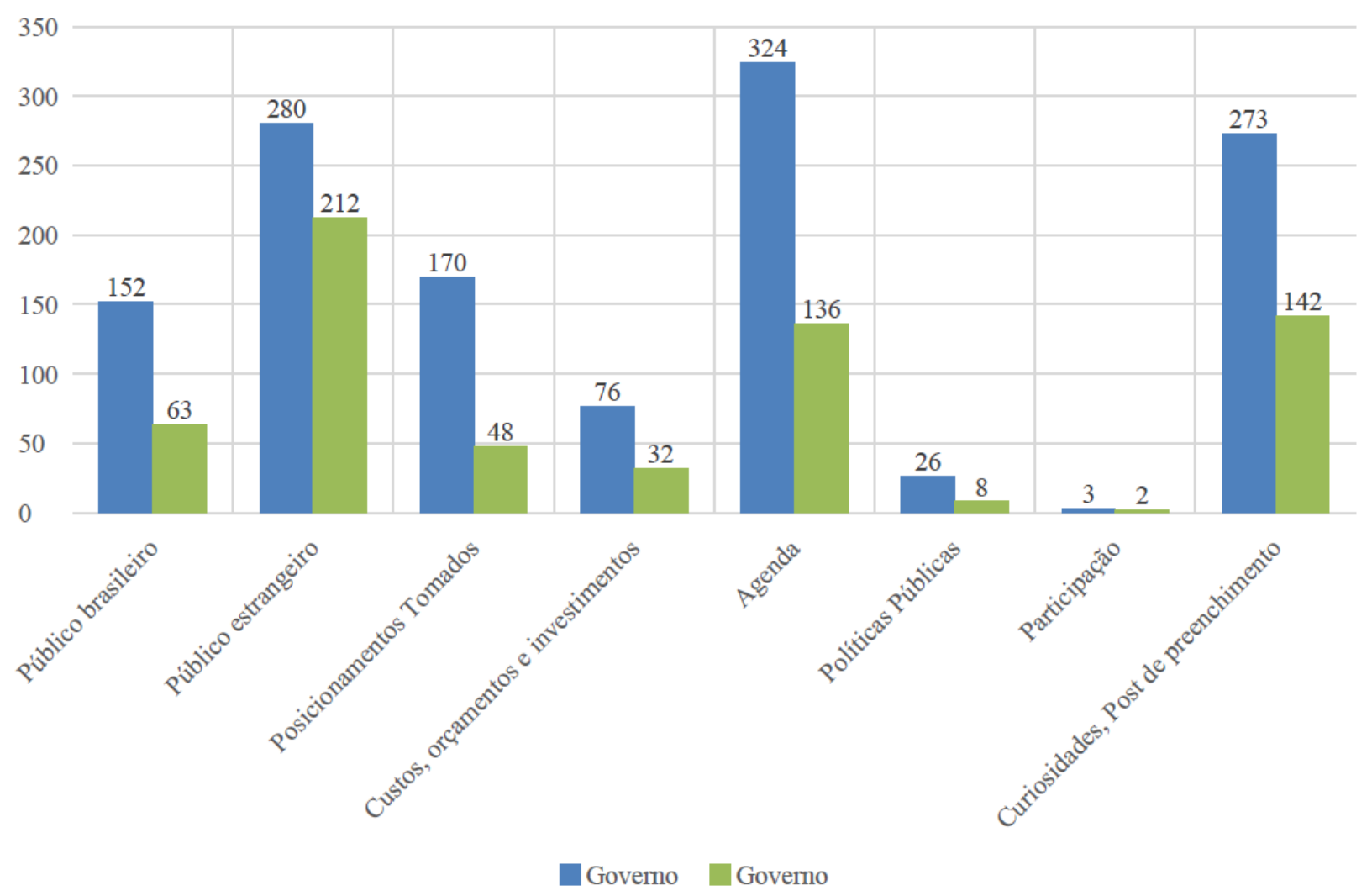

Fonte: AUTORA, 2020.

O Gráfico 4 demonstra o cruzamento entre o período governamental, as variáveis qualitativas e o volume de engajamento. Apesar do governo Dilma Rousseff apresentar o maior número de posts e o maior número de manifestações dentro das variáveis qualitativas, como descritas nos Gráficos 1 e 3, a mesma configuração não permanece quando adicionamos a variável Volume de Engajamento. O governo Dilma Rousseff é o que possui maior engajamento em Custos/Orçamentos/Investimentos, seguido logo atrás de Ações de Diplomacia/Comunicação para Público Brasileiro, Políticas Públicas e Ações de Diplomacia/Comunicação para Público Estrangeiro. As variáveis Agenda, Curiosidades/Post de preenchimento, e principalmente, Participação, possuem configurações em engajamento semelhantes à do governo Michel Temer. Entretanto, o diferencial no Gráfico 4 é a variável Posicionamento.

Apesar de Posicionamento só ser a quarta maior categoria em que o governo Rousseff apresente resultados elevados, ainda é mais que o dobro do que o governo Temer - como é observado no Gráfico 3. Mas, quando adimos os valores das médias de Volume de Engajamento, o governo Temer possui um terço a mais de engajamento nessa categoria do que o governo Rousseff. 
Gráfico 4: Governo X Variáveis X Volume de engajamento.

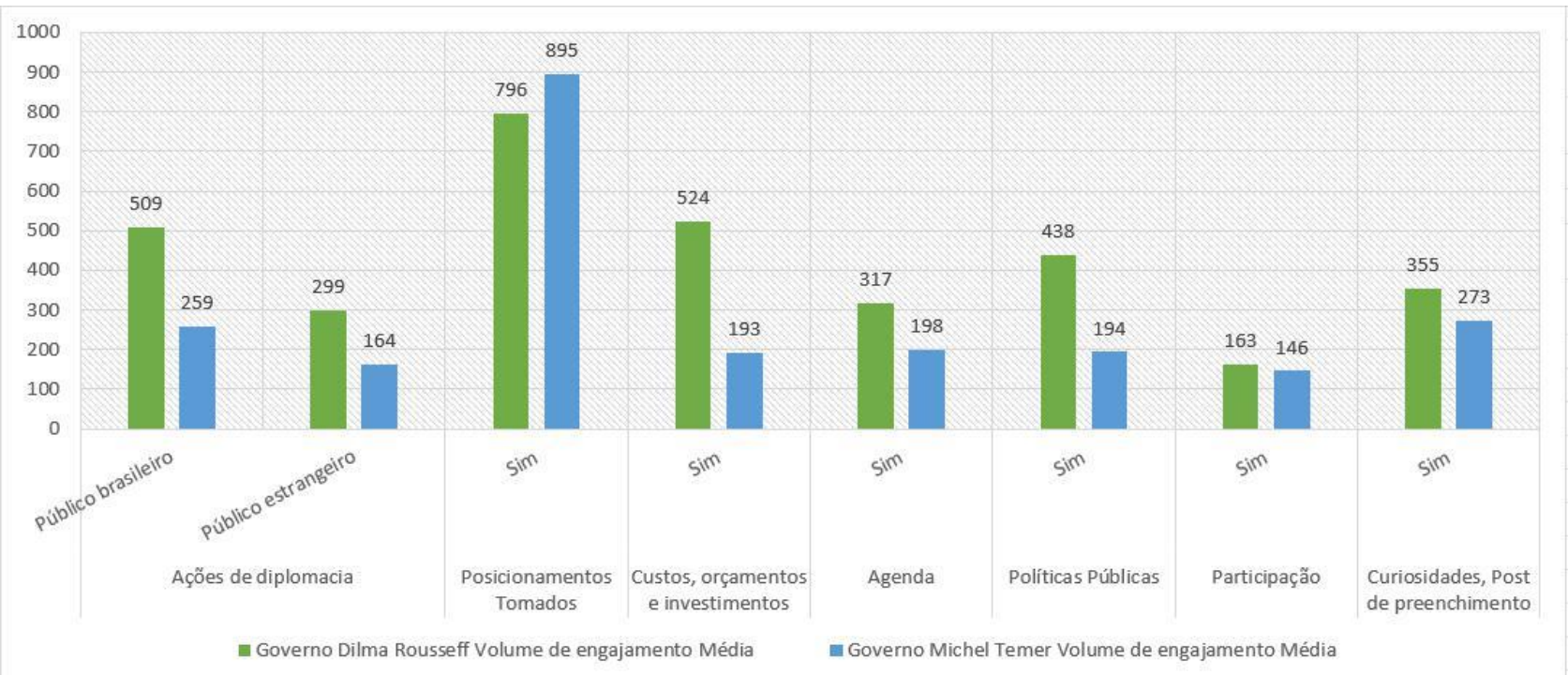

Fonte: AUTORA, 2020.

\section{DISCUSSÃO E CONSIDERAÇÕES FINAIS}

O caminho percorrido até aqui no artigo, de maneira geral, buscou a análise das 1562 publicações da página do Facebook do Ministério das Relações Exteriores em relação as 8 variáveis qualitativas, levando em ponderação o referencial teórico e principalmente, a intersecção teórica entre Comunicação Pública, Diplomacia Pública e a sua variante, Diplomacia Pública 2.0. As informações descritas nos gráficos e tabelas fomentaram alguns questionamentos.

Dos resultados obtidos na pesquisa podemos destacar a convergência da comunicação e a diplomacia pública quando o seu público alvo é a sociedade civil interna, o cidadão brasileiro, e a variável que busca averiguar ações voltadas para esse público são as Ações de Diplomacia/Comunicação voltadas para o Público Brasileiro. O número de postagens desta variável não está entre os níveis mais baixos de ocorrências e possui o segundo maior nível em média de engajamento, praticamente o dobro do engajamento encontrado na variável voltada para públicos estrangeiro. Logo, o Itamaraty divulga mais ações de diplomacia/comunicação para público estrangeiro, o que é em sua maioria contraditório, uma vez que as publicações analisadas foram retiradas da página oficial em português do ministério e não de contas em inglês ou espanhol que foram criadas para atender pessoas de outras nacionalidades.

Destaca-se também, a variável Posicionamento com o maior nível de engajamento, mas com volume de ocorrências em nível intermediário. Assim, os usuários, e mais especificamente a sociedade civil brasileira com acesso à internet e usuária da rede social Facebook, se engajam mais 
na página oficial do ministério quando os posts apresentam diretrizes na forma de Estado Nação, ou seja, a representatividade democrática destes mesmos cidadãos.

Uma das descobertas desta pesquisa foi a desvalorização do fomento a participação pelas postagens do Itamaraty, ponto que o ministério e todas as correntes teóricas aqui explanadas mais destacam. A variável Participação é aquela que apresenta o nível mais baixo de ocorrência e a menor média de engajamento. Entretanto, não é possível afirmar que esse baixo nível de engajamento é acarretado por baixo nível de ocorrências, uma vez que a variável Políticas Públicas também possui baixo nível de ocorrência, mas uma média significativa de volume de engajamento.

Outro ponto a ser destacado é a não ocorrência de transparência e prestação de contas na categoria Custos, Orçamentos e Investimentos, quando o assunto é especificamente o ministério. Só é vista um post apresentado desta forma. A fatal deste tipo de post é prejudicial para a legitimação da instituição de origem democrática.

E o último destaque nos resultados é referente ao período governamental. As variáveis que mais utilizadas pelo governo Dilma Rousseff são Agenda, Ações de Diplomacia/Comunicação voltada para Público Estrangeiro, Curiosidades/Post de preenchimento e Posicionamento, respectivamente do maior para o menor, e, no governo Michel Temer são as Ações de Diplomacia/Comunicação voltada para o Público Estrangeiro, as Curiosidades/Post de preenchimento e a Agenda. Ou seja, os níveis de ocorrências podem ser diferentes em cada governo, mas as variáveis mais priorizadas continuaram as mesmas. O período governamental de Dilma Rousseff é o que apresenta mais ocorrências na variável do tipo Posicionamento em comparação com o período governamental de Michel Temer, mas a média de engajamento não possui a mesma configuração, dado que é no período governamental de Michel Temer que essa variável possui uma maior média de engajamento.

Assim, o Ministério das Relações Exteriores faz comunicação pública no Facebook quando associada a área de diplomacia pública, e, por conseguinte, diplomacia 2.0 em uma primeira análise. Entretanto, as postagens na sua maioria não priorizam questões como transparência e participação-elementos chaves na comunicação pública e na diplomacia pública- e questões de para quem é o público alvo das publicações.

Então, utilizar os "media" sociais, os sites de redes sociais e todas as outras possibilidades oferecidas pela realidade conectada à Internet pode ser sim um impulso em tentar se aproximar dos cidadãos brasileiros e possibilitar que valores democráticos sejam mais garantidos. Mas, se mal 
utilizada, pode representar-se ineficaz ao objetivo pretendido, como é o caso de Custos/Orçamentos/Investimento.

É necessário reconhecer algumas limitações na presente pesquisa. A primeira é que algumas questões ultrapassam o espaço das redes sociais digitais e também que o Facebook é apenas uma parte de um grande cenário complexo de ações democráticas, políticas e sociais. A segunda é a diferença na quantidade representativa do número de $\mathrm{N}$ de cada governo, ou seja, não podemos extrapolar os resultados para outros anos de cada governo, somente para uma análise inicial da página oficial.

Não obstante, a proposta de analisar o Ministério através das intersecções teóricas das três correntes teóricas possibilita novos caminhos de analises interdisciplinares.

\section{REFERÊNCIAS}

ALBA Z, Carlos García. Diplomacia pública, propaganda y poder blando. Revista Mexicana de Política Exterior, México, n. 85, p.221-228, 2009.

ALMADA, M. P., ROSSETTO, G. N. P., \& CARREIRO, R. (2014). Diferentes objetivos, diferentes apropriações? O uso do Facebook por iniciativas civis de democracia digital no Brasil. Verso e Reverso, 28(68), 145-154.

BRASIL. Constituição Federal de 88. Disponível em: http://www.planalto.gov.br/ccivil_03/constituicao/constituicao.htm. Acessado em: 10/06/2020.

BRASIL. Presidência da República. Secretaria Especial de Comunicação Social. Pesquisa brasileira de mídia 2016: hábitos de consumo de mídia pela população brasileira. - Brasília: Secom, 2016. 120 p.: il.

CULL, Nicholas. Public diplomacy: taxonomies and histories. The annals of the American Academy of political and social science, v. 616, n. 1, p. 31-54, 2008.

CULL, Nicholas. Public diplomacy: lessons from the past. Figueora Press, CPD Perspectives on Public diplomacy, v. 2, n. 19, Los Angeles, 2009.

CULL, Nicholas. The Long Road to Public Diplomacy 2.0: The Internet in U.S. Public Diplomacy. International Studies Review, v. 15, n. 1, p. 123-139, 2010.

DAHLBERG, Lincoln. Democracy via cyberspace: Mapping the rhetorics and practices of three prominent camps. New media \& society, v. 3, n. 2, p. 157-177, 2001.

ITAMARATY. Ministério das Relações Exteriores. Disponível em: http://www.itamaraty.gov.br/pt-BR/. Acessado em 20/06/2019. 
LÓPEZ, Juan Camilo Jaramillo. Proposta geral de comunicação pública. In: DUARTE, Jorge. Instrumentos de comunicação pública. Pública: Estado, mercado, sociedade e interesse público. $3^{\text {a }}$ ed., p. 246-267 São Paulo, Atlas, 2012

KIRKPATRICK, D. O efeito Facebook: Os bastidores da história da empresa que conecta o mundo. Rio de Janeiro: Intrínseca, 2011.

KOÇOUSKI, Marina. Comunicação pública: construindo um conceito. In: MATOS, Heloiza (Org.). Comunicação pública: interlocuções, interlocutores e perspectivas. p. 71-96. São Paulo: ECA/USP, 2012.

MARQUES, Francisco Paulo Jamil Almeida. Ciberpolítica: conceitos e experiências. Salvador EdUfba, 2016.

MIOLA, Edna. MARQUES, F. P. J. Por uma definição de comunicação pública: tipologias e experiências brasileiras. Compolítica, Porto Alegre, 2017.

NASCIMENTO, Lebna Landgraf. Comunicação pública nas redes sociais digitais. In: MATOS, Heloiza (Org.). Comunicação pública: interlocuções, interlocutores e perspectivas. p. 289-309. São Paulo: ECA/USP, 2012.

NOYA, Javier. Una diplomacia pública para España. Real Instituto Elcano de Estudios Internacionáles y Estratégicos, España, 2006.

NORRIS, Pippa. Digital divide: Civic engagement, information poverty, and the Internet worldwide. Cambridge University Press, 2001.

PERON, Vivian. Mídias sociais e diplomacia pública no Brasil e EUA: um estudo de diplomacia digital através do twitter. Compolítica, Porto Alegre, 2017.

RIEDER, Bernhard. Estudando o Facebook através da extração de dados: o aplicativo Netvizz. Em: Procedimentos da $5^{\text {a }}$ conferência anual de ciências da web da ACM. p. 346-355. ACM, 2013

ROLO, Aline Pedrosa. Teoria e prática da diplomacia digital: a comunicação político diplomática nas redes sociais e o caso de Portugal. Dissertação. Universidade de Coimbra, 2014.

RUBIO, Rafael. Diplomacia digital: una introducción. Las relaciones internacionales en el tránsito al siglo XXI. Cuadernos de la escuela diplomática, España, 2011.

WE ARE SOCIAL. DIGITAL 2019: global digital yearbook. Disponível em : https://datareportal.com/reports/digital-2019-global-digital-

yearbook?utm_source=Reports\&utm_medium=PDF\&utm_campaign=Digital_2019\&utm_content= Global_Overview_Promo_Slide. Acessado em: 29/06/2020.

ZÉMOR, Pierre. As formas da comunicação pública. In: Duarte, Jorge (org.). Comunicação Pública: Estado, mercado, sociedade e interesse público. $3^{\text {a }}$ ed. São Paulo, Atlas, 2012. p. 214-245. 